\title{
Corrosion Inhibition of mild steel in Acid Media by Alpina galinga Extract
}

\author{
S.Ananth Kumar ${ }^{\mathrm{a}}$ Dr.A.Sankar* ${ }^{\mathrm{A}}$, S.Rameshkumar ${ }^{\mathrm{b}}$ \\ ${ }^{a}$ Kandaswami Kandar's College, P. velur, Namakkal-638 182, India \\ ${ }^{b}$ PSG College of Technology Peelamedu, Coimbatore 641 004, India
}

\begin{abstract}
The corrosion inhibition nature of Alpina galinga extract for the corrosion of mild steel in $0.5 \mathrm{~N}$ $\mathrm{H}_{2} \mathrm{SO}_{4}$ was investigated using weight loss, electrochemical impedance and potentiodynamic polarization methods. The results revealed that Alpina galinga extract acts as a corrosion inhibitor in $0.5 \mathrm{~N} \mathrm{H}_{2} \mathrm{SO}_{4}$ medium. The inhibition efficiency increased with an increase in inhibitor concentration. The inhibition is attributed to adsorption of the inhibitor on the steel surface.
\end{abstract}

Key words: Inhibitor, Mass loss, Impedance, Polarization, Ginger affinale

\section{Introduction}

Environmental friendly inhibitors have attracted several researchers. Nontoxic natural products have been widely used as corrosion inhibitors. Natural products such as tannins [1-3] have been used as inhibitors. Extracts of plants such as cerampetroselinum, Lupine,Doum and organgesheels have been used as corrosion and scale inhibitors[4]. Pomegranate [5],Swertiaaungustitolia [6] and Azadiractaindica [7]have a good inhibitive property. The scale inhibitionefficiencies of the aqueous extracts of plant materials, namely CordiaLatifolia, Eucalyptus and Jasmine auriculatum have been evaluated [8]. Caffeine has been used as inhibitor in controlling corrosion of mild steel immersed in an aqueous solution containing 60ppm of Cl-[9]. Longo, et al [10], synthesized a number of different porphyrins and their metallic derivatives and used them as corrosion inhibitors for pure iron (Armco) and pure aluminium in $1 \%$ sodium chloride $(\mathrm{NaCl})$ solution. Award has used the extracts of the plants Calotropisprocera and Diopyrosmesipilioforms to control corrosion of mild steel in $0.1 \mathrm{~N}$ hydrochloric acid $(\mathrm{HCl})$ solutions, by adopting weight loss measurements and polarization studies [11]. The present work investigated the inhibition efficiency of an Methanolic extract of plant material, Alpine galinga extract, in controlling corrosion of carbon steel (CS) immersed in an $0.5 \mathrm{~N} \mathrm{H}_{2} \mathrm{SO}_{4}$ solution containing in the absence and presence of KI using a mass loss study, potentiodynamic polarization and impedance methods.

\section{Preparation of extract.}

\section{Materials And Methods}

An methanolic extract of Alpine galinga was prepared by powdered extracted with boiling methanol, then removes gangues from the suspended one. The extract was used as corrosion inhibitor in the present study.

\section{Preparation of specimens}

Carbon steel specimens $(0.022 \% \quad \mathrm{~S}, 0.038 \% \quad \mathrm{Mn}, 0.027 \% \mathrm{P}, 0.086 \quad \mathrm{C})$ of dimensions $1.0 \mathrm{~cm}$ $* 4.0 \mathrm{~cm} * 0.2 \mathrm{~cm}$ were polished to a mirror finished and degassed with using trichloroethylene.

\section{Mass loss method.}

Relevant data on the $0.5 \mathrm{~N} \mathrm{H}_{2} \mathrm{SO}_{4}$ used in the study are given in table 1. Carbon steel specimens in triplicate were immersed in $100 \mathrm{~mL}$ of the solutions containing various concentrations of the inhibitor in the presence and absence of KI for two hours. The weight of the specimens before and after immersion was determined using shimadzu balance model Ay 62.The inhibition efficiency (IE) was then calculated using the equation.

$$
I E \%=\left[\frac{W_{1}-W_{2}}{W_{1}}\right] \times 100
$$

Where $\mathrm{W}_{1}$ and $\mathrm{W}_{2}$ are the corrosion rates in the absence and presence of the inhibitor, respectively.

\section{Electrochemical measurements}

\subsection{Impedance measurements}

The electrochemical impedance measurements were carried out using a Potentiostat/Galvanostat/FRA (PARSTAT 2273, Princeton Applied Research, USA). Data acquisition was performed utilizing the PowerSuite software and analyzed using ZsimpWin software(version 3.21). A three electrode set up was employed with Pt foil as the auxiliary electrode and a saturated calomel electrode as reference electrode. The mild steel cylinder, 
with surface prepared as described in the weight loss experimental method, served as the working electrode. The measurements were carried out in the frequency range $10^{6}-10^{-2} \mathrm{~Hz}$ at the open circuit potential by superimposing a sinusoidal AC signal of small amplitude, $10 \mathrm{mV}$, after immersion for $30 \mathrm{~min}$ in the corrosive media. The double layer capacitance $\left(\mathrm{C}_{\mathrm{dl}}\right)$ and charge transfer resistance $\left(\mathrm{R}_{\mathrm{ct}}\right)$ were obtained

from the impedance plots as described elsewhere [12]. Because Rct is inversely proportional to corrosion current density, it was used to determine the inhibition efficiency (IE\%) using the relationship:

$$
\mathrm{IE} \%=\frac{\text { Rct }-\mathbf{R}^{\circ} \mathrm{ct}}{\text { Rct }} \times 100
$$

where $R_{\mathrm{ct}}$ and $\underline{\mathrm{R}^{\circ} \mathrm{ct}}$ are the charge transfer resistance values in the uninhibited and inhibited solutions respectively.

\subsection{Polarization measurements}

The potentiodynamic polarization curves were recorded using the same cell setup employed for the impedance measurements. The potentials were swept at the rate of $1.66 \mathrm{mVs}-1$, primarily from a more negative potential than $\mathrm{E}_{\text {ocp }}$ to a more positive potential than $\mathrm{E}_{\text {ocp }}$ through $\mathrm{E}_{\text {corr }}$. The inhibition efficiencies were calculatedusing the relationship [13]:

$$
\mathrm{IE} \%=\frac{\mathrm{I}^{\circ} \mathrm{corr}-\mathrm{Icorr}}{\mathrm{I}^{\circ} \mathrm{corr}} \times 100
$$

where $I_{\text {corr }}^{0}$ and $I_{\text {corr }}$ are the corrosion current densities in the absence and in the presence of inhibitor, respectively.

\section{Results And Discussion}

Analysis of result of mass loss method

The corrosion rate (CR) of carbon steel immersed in $0.5 \mathrm{~N} \mathrm{H}_{2} \mathrm{SO}_{4}$ in the absence and presence of inhibitor systems are given table 2. The inhibition effiencies (IE) are also given in this tables.

It is seen from table. 2 that the rizhome extract of Alpina galinga shows $38.92 \%$ in $0.5 \mathrm{~N} \mathrm{H}_{2} \mathrm{SO}_{4}$ inhibition efficiency for the corrosion of carbon steel in well water and it increases with increase in volume of stock solution added to the corrosive media.

Table1.Corrosion rate (CR) of carbon steel in $0.5 \mathrm{~N} \mathrm{H2SO}$ in the absence and presence of inhibitors, and the inhibition efficiency (IE) obtained by mass loss method.

\begin{tabular}{|c|c|c|c|c|}
\hline \multirow{2}{*}{$\begin{array}{c}\mathrm{AC} \\
\text { Extract } \\
(\mathbf{p p m})\end{array}$} & \multicolumn{2}{|c|}{ KI (0)ppm } & \multicolumn{2}{|l|}{ KI (50)ppm } \\
\hline & $\begin{array}{c}\mathrm{CR} \\
\left(\mathrm{mg} \mathrm{cm}^{-2} \mathrm{~h}^{-1}\right)\end{array}$ & IE & $\begin{array}{c}\mathrm{CR} \\
\left(\mathrm{mg} \mathrm{cm}^{-2} \mathbf{h}^{-1}\right)\end{array}$ & $\begin{array}{l}\text { IE } \\
\%\end{array}$ \\
\hline 0 & 112.81 & & 112.81 & \\
\hline 10 & 68.90 & 38.92 & 34.69 & 69.25 \\
\hline 25 & 65.63 & 41.91 & 33.44 & 70.35 \\
\hline 50 & 62.81 & 44.32 & 32.50 & 71.19 \\
\hline 100 & 56.88 & 49.57 & 31.88 & 71.75 \\
\hline
\end{tabular}

Immersion period: 2 hours; Inhibitor :MethanolicExtract of Alpine galinga(AG)-KI.

Electrochemical impedance spectroscopic measurements (EIS)

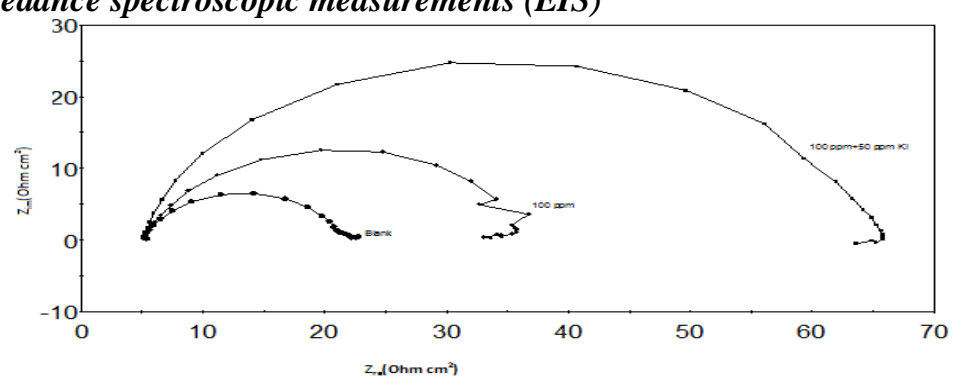

The Impedance measurements of mild steel immersed in sea water in the absence and presence of inhibitors are in Fig 2.

Table 2. Impedance parameters obtained from electrochemical impedance studies. 
Corrosion Inhibition of mild steel in Acid Media By Alpina galinga Extract

\begin{tabular}{|l|l|l|l|}
\hline $\begin{array}{l}\text { Inhibitor } \\
\text { concentration } \\
\text { ppm }\end{array}$ & $\begin{array}{l}\text { Rct } \\
\text { Ohm } \mathrm{cm}^{2}\end{array}$ & $\begin{array}{l}\mathbf{C}_{\mathrm{dl}} \\
\boldsymbol{\mu F}\end{array}$ & IE\% \\
\hline $\mathbf{0}$ & 17.2 & $\mathbf{9 . 2 5 7 8 \times 1 0 ^ { - 3 }}$ & \\
\hline 100 & 39 & $1.0149 \times 10^{-5}$ & 55.89 \\
\hline $\begin{array}{l}100 \mathrm{ppm}+ \\
\mathbf{5 0 p p m}(\mathrm{KI})\end{array}$ & 62 & $6.384 \times 10^{-6}$ & $\mathbf{7 2 . 2 5}$ \\
\hline
\end{tabular}

Impedance spectra obtained for corrosion of mild steel in $0.5 \mathrm{~N} \mathrm{H}_{2} \mathrm{SO}_{4}$ contains two semicircles in which the second one represents the interaction of metal surface with the corrosive environment . The first semicircle represents the nature of the corrosive media .Since the conductivity of the corrosive medium is very low ,this also behaves like a leaky capacitor . The CR-CR model best describes this situation. The second semicircle in the impedance plots contain depressed semicircles with the centre below the real axis. The size of the semicircle increases with the inhibitor concentration, indicating the charge transfer process as the main controlling factor of the corrosion of mild steel. It is apparent from the plots that the impedance of the inhibited solution has increased with the increase in the concentration of the inhibitor. The experimental results of EIS measurements for the corrosion of mild steel in $0.5 \mathrm{~N} \mathrm{H}_{2} \mathrm{SO}_{4}$ in the absence and presence of inhibitor are given in Table 2.Papova et al. said that sum of charge transfer resistance (Rct) and adsorption resistance (Rad) is equivalent to polarization resistance $(\mathrm{Rp})$.

\section{Polarization studies :}

Electrochemical parameters like corrosion potential $\left(\mathrm{E}_{\text {corr }}\right)$,corrosion current density $\left(\mathrm{I}_{\text {corr }}\right)$,cathodic tafel slope $\left(\beta_{\mathrm{c}}\right)$ Anodic tafel slope $\left(\beta_{\mathrm{a}}\right)$ and percentage inhibition efficiency according to polarization studies are listed in table 3. Here $\mathrm{I}_{\text {corr }}$ decreased with increasing inhibitor concentration. It is clearly observed that the Ginger afinale reduce the corrosion current density.

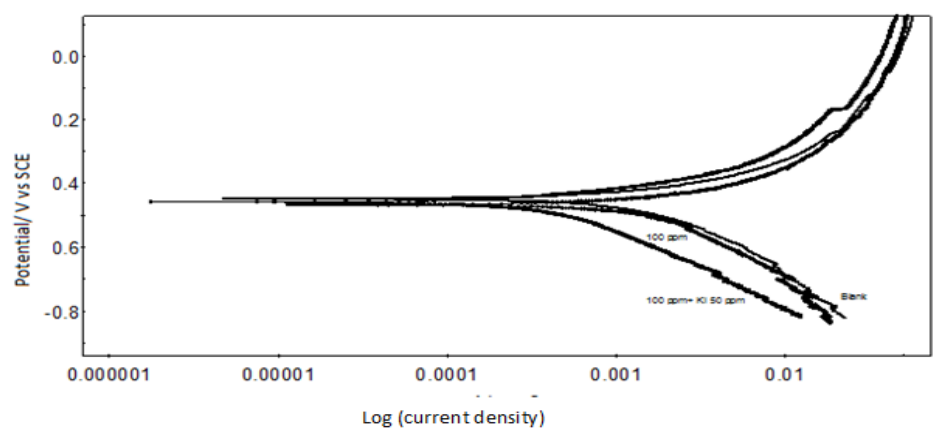

The potentiodynamic polarization curves of mild steel immersed in sea water in the absence and presence of inhibitors are in Fig 2.

Table 3. Corrosion parameters in the presence and absence of inhibitor obtained from polarization measurements.

\begin{tabular}{|l|l|l|l|l|l|}
\hline $\begin{array}{l}\text { Inhibitor } \\
\text { concentration } \\
(\mathrm{ppm})\end{array}$ & $\begin{array}{l}-\mathrm{E}_{\text {corr }} \\
(\mathrm{mV})\end{array}$ & $\beta_{\mathrm{c}}(\mathrm{mV} /)$ & $\beta_{\mathrm{a}}(\mathrm{mV})$ & $\begin{array}{l}\text { Icorr×10*6 } \\
\mu \mathrm{A}\end{array}$ & $\mathrm{IE} \%$ \\
\hline 0 & 448 & 127 & 68 & 1.628 & 0.619 \\
\hline 100 & 446 & 133 & 69 & 0.210 & 62.0 \\
\hline $100+50$ ppmKI & 472 & 168 & 78 & & 87.1 \\
\hline
\end{tabular}

Corrosion current density decreased noticeably with inhibitor concentration, indicating the increased inhibition efficiency with the increase in the concentration of the inhibitor. $\mathrm{E}$ corr value shifted towards more negative potential .It has been reported that a compound can be classified as an anodic and cathodic type inhibitor on the basis of shift $\mathrm{E}_{\text {corr }}$ value.If displacement of $\mathrm{E}$ corr value is greater than $85 \mathrm{mv}$, towards anode or cathode with reference to the blank, then an inhibitor is categorized as either anodic or cathodic type inhibitor .otherwise inhibitor is treated as mixed type. In our study, maximum displacement in $\mathrm{E}$ corr value was around around $24 \mathrm{mV}$. Indicating inhibitor is a mixed type inhibitor with more anodic nature.$\beta \mathrm{c}$ and $\beta \mathrm{a}$ values changed with respect to the inhibitor concentration. Therefore, Alpina galinga extract could be classified as a mixed type inhibitor suggesting that the presence of the inhibitor does not alter the reaction mechanism, and that the inhibition effect has occurred due to simple blocking of the active sites, thereby reducing available surface area of the corroding metal. [14-15]

Active principle for corrosion 
Adsorption of organic molecules may be explained by the presence of an oxygen atom (a hetroatom), electron of aromatic rings and electron donating groups. The hetro-atoms such as oxygen are the major adsorption center in organic compounds for its interaction with the metal surface [17]. The adsorption can also occur via electrostatic interaction between a negatively charged surface, which is provided by a specifically adsorbed anion $\left(\mathrm{Cl}^{-}\right)$on iron, and the positive charge of the inhibitor [18]This observation suggests that inhibitor molecules adsorb on the metal surface by blocking the active sites on the metal surface [16]

The active principle for corrosion inhibition is an aqueous methanolic extract of Alpina galinga is having 1'acetoxychavicol acetate (1) and 1'-acetyl eugenol acetate compound

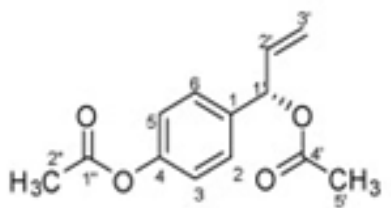

1'S-1'-acetoxychavicol acetate, 1

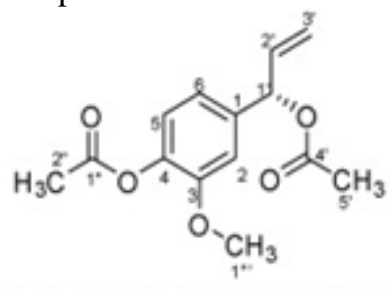

1'S-1'-acetoxyeugenol acetate, 2

\section{1 '-acetoxychavicol acetate (1) and 1'-acetyl eugenol acetate}

\section{Conclusions}

1. Plant inhibitors inhibited mild steel corrosion in Acid solutions.

2. Corrosion inhibition of mild steel in acid solution is under mixed control.

3. Inhibition efficiency of plant extracts increases with increase in concentration.

4. The mass loss measurements are in good agreement with electrochemical method.

5.From the results obtained we can conclude the following. Alpina galinga perfectly inhibits the corrosion of a mild steel in $0.5 \mathrm{~N} \mathrm{H}_{2} \mathrm{SO}_{4}$ solution, The high inhibition efficiency is attributed to the strong adsorption of AG on the MS surface

[1] J.P.Moresby, Corros. Australas 10 (1988) 10

\section{Reference}

[2] J.I.Bregman, Corrosion Inhibitors (New york, NY,London, UK :Macmillion, (1963) 33,48,99,107.

[3] U.R.Evans, The corrosion and oxidation of Metals (London, UK, Edward Arnold Ltd., 1960) 170, $171,178$.

[4] A.A.E1 - Hosary, R.M.Saleh, H.A.E1-Dahan, "Corrosionand Scale inhibition in cooling water byNaturally Occuring Substance", "Proc.of $7^{\text {th }}$ European symp. On Corrosion Inhbibitors (Ferrara,Italy: University of Ferrara), 1 (1990) 725

[5] A.A. E1-Hosary, R.M. Saleh, A.M.Shans El Din,Corros. Sci. 12 (1972) 897.

[6] S.J. Zakvi, G.N. Mehta, J.Electrochem Soc. 37(1988) 237.

[7] M.Manimegalai, P.Rajeswari, S.Mohanam, S.Maruthamuthu, N.Palanisawamy "Biocidal and InhibitionEffect of Naturally OccuringSubstacnes -Azodiractaindica on mild steel in fresh water", Procof 10th National congress on corrosion control, heldsept 6-8 (Madurai, India, 2000) 153.

[8] I.H. Farooqui, M.A. Quraishi, "Break through inSclae and Deposit Control. Quert Publication,Mumbai, India.Sponsor : NACE International, India Section, Corrosion Sci. Society of India", Procof Industrial Corrosion causes and MitigationCORCON 2000 (Mumbai, India), 2 (2000) 103.

[9] S.Rajendran, S.Vaibhavi, N.Anthony, D.C. Trivedi,Corrosion 59 (2003) 529.

[10] F.R.Longo, J.J.DeLuccia, V.S.Agarwala, "Prophyrinsas corrosion inhibitors", Proc. 6th Europeansymp. On corrosion inhibitors, vol.1 (Ferrara, Italy: University of Ferrara, 1985) 155.

[11] G.H.Awad, "Effect of some plant Extracts on thecorrosion of Mild steel in 0.1 N Hydrochloric Acidsolution", Proc. 6th European symp. On corrosioninhibitors, vol.1 (Ferrara, Italy: University ofFerrara, 1985) 385.

[12]. H. Ashassi-Sorkhabi, B. Shaabani, D. Seifzadeh, Electrochim. Acta 50 (2005) 3446

[13]. M. Shahin, S. Bilgie, H. Yilmaz, Appl. Surf. Sci. 195 (2003) 1.

[14] Felicia Rajammal Selvarani, S.Santhanalakshmi, J. Wilson sahayaraja, A. John Amalraj,and Susai Rajendran , Bull. Electrochemistry. 20 (2004) 561-565.

[15] Susai RajendranS. Mary Reenkala, Noreen Anthonyand R. Ramaraj Corros Sci, 44 (2002) 2243-2252.

[16]. H. Ashassi-Sorkhabi, B. Shaabani and D. Seifzadeh, Electrochimica Acta,50(2005) 3446

[17]. E. Rocca, C. Rapin and F. Mirambet, Corrosion Science,46(2004)653

[18]. K. Tebbji, H. Oudda, B. Hammouti, M. Benkaddour, M. El Kodadi and A. Ramdani, Colloids and Surfaces A: Physicochem. Eng. Aspects259(2005)143 